\title{
A CLINICAL AND BIOCHEMICAL STUDY OF A TRIAL OF IPRONIAZID IN THE TREATMENT OF DEPRESSION
}

\author{
BY
}

\section{M. B. PARE and M. SANDLER*}

\section{From Bethlem Royal and Maudsley Hospitals, London, and the Royal Free Hospital School of Medicine, London}

Iproniazid (isopropylisonicotinic acid hydrazide) is a compound with a marked antibacterial action against $M$. tuberculosis. Although a number of clinical trials have shown it to be effective against tuberculosis, side-effects are common, so that it has been largely superseded by the relatively nontoxic compound, isoniazid. As one of the more frequent of these side-effects is euphoria, several groups of workers have given iproniazid empirically to depressed patients and reported improvement.

There has been much speculation about the mechanism by which this benefit might be obtained but little direct corroborative evidence. It is known that iproniazid has a marked inhibitory action on monoamine oxidase (Zeller and Barsky, 1952), the enzyme largely responsible for inactivation of 5-hydroxytryptamine (5HT) (Sjoerdsma, Smith, Stevenson, and Udenfriend, 1955). A proportion of the naturally occurring catechol amines are also inactivated by this mechanism (von Euler, 1956). In the experimental animal, it has been shown that changes in the brain concentration of 5HT and catechol amines are associated with alterations in the behaviour of the animal. Thus, the decrease in brain concentration of these substances obtained after treatment with reserpine results in behaviour compatible with a state of depression (Brodie, Pletscher, and Shore, 1955; Carlsson, Lindquist, Magnusson, and Waldeck, 1958), whilst an increase, obtained by administration of a precursor substance, leads to excitement (Bogdanski, Weissbach, and Udenfriend, 1958; Carlsson et al., 1958). Iproniazid similarly leads to increased brain levels, with associated excitement (Spector, Prockop, Shore, and Brodie, 1958).

In man, reserpine has a tendency to induce a state of depression (Lemieux, Davignon, and Genest, 1956; Deshaies, Richardeau, and Dechosal, 1957), and also liberates 5HT from its binding sites in platelets (Carlsson, Shore, and Brodie, 1957), although there have been no direct observations on brain tissue. Conversely, iproniazid, which may

*Present address: Queen Charlotte's Hospital, London. cause euphoria, causes increased concentrations of 5HT in human platelets (Pletscher and Bernstein, 1958). Furthermore, electroconvulsive therapy is established as a method of treatment for depression in psychiatric practice, and in animals temporarily increases the concentration of 5HT in the brain but not in other organs (Garattini and Valzelli, 1957).

Although there is no evidence to suggest that the depressive illnesses seen in clinical practice are due to a deficiency of 5HT or catechol amines, it is not unreasonable to postulate that any improvement obtained with iproniazid may be connected with altered concentrations of these substances. Despite some enthusiastic reports, the degree of benefit that can be obtained is difficult to assess from the literature, for, so far as we are aware, no attempt at a controlled trial has yet been published.

The present investigation was, therefore, designed to answer the following questions:-

(1) Does iproniazid benefit patients with depression?

(2) If so, can the patients who respond be differentiated clinically or biochemically from those who do not?

(3) In patients who respond to iproniazid, is the benefit due to changes in the concentrations in the brain of 5HT or of catechol amines?

\section{Method}

Fifty patients with depression (Table I) who had been considered suitable for electroconvulsive therapy were given iproniazid in doses of 150 to $450 \mathrm{mg}$./day for periods varying from two to 40 weeks. Placebo was substituted in certain cases. The first few patients were also given reserpine, $1 \frac{1}{2}$ to $4 \frac{1}{2} \mathrm{mg}$./day, seven to 10 days after starting iproniazid : this was found to be unnecessary and was discontinued. The degree of depression was assessed by weekly rating scales which were completed by the registrar in charge of the case, who was unaware when placebo tablets were being used (Table II). Patients were said to respond to iproniazid if the depression improved with treatment, relapsed when placebo was substituted, and improved again when iproniazid was reintroduced. Patients who improved with iproniazid but did not relapse when placebo was substituted had 
TABLE I

50 CASES OF DEPRESSION TREATED WITH IPRONIAZID

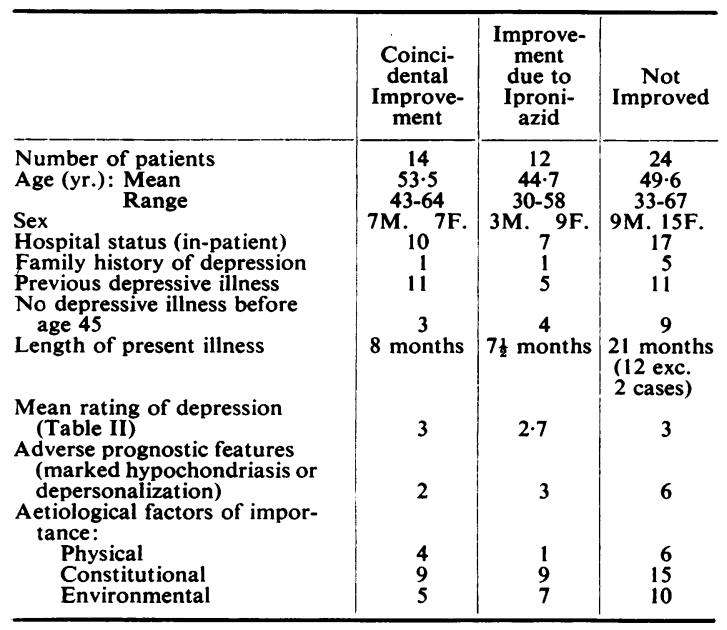

TABLE II

RATING SCALE

\begin{tabular}{|c|c|c|}
\hline Mental Condition & & Rating \\
\hline Depression & $\begin{array}{l}0 \\
1 \\
2 \\
3\end{array}$ & $\begin{array}{l}\text { Marked (actively wishes to die or no interest } \\
\text { in living) } \\
\text { Mild } \\
\text { Not depressed } \\
\text { Elated }\end{array}$ \\
\hline Retardation & $\begin{array}{l}1 \\
2 \\
3\end{array}$ & $\begin{array}{l}\text { Marked (needs constant nursing attention } \\
\text { or encouragement to fulfil essential per- } \\
\text { sonal needs) } \\
\text { Mild } \\
\text { Not retarded } \\
\text { Overactive }\end{array}$ \\
\hline $\begin{array}{l}\text { Interest in social } \\
\text { activities }\end{array}$ & $\begin{array}{l}0 \\
1 \\
2\end{array}$ & $\begin{array}{l}\text { Will not participate } \\
\text { Some participation with encouragement } \\
\text { Willing but passive participation, e.g., } \\
\text { spectator role } \\
\text { Willing and active participation }\end{array}$ \\
\hline
\end{tabular}

necessarily to be designated as "coincidental" improvement.

Early morning specimens of urine were collected before and at weekly intervals after treatment was started. 5-Hydroxyindoleacetic acid (5HIAA) was estimated as mg./g. creatinine by the method of Udenfriend, Titus, and Weissbach (1955). Creatinine was measured by a Lloyd's reagent absorption method (Hare, 1950). The identity of the 5HIAA was confirmed by the extraction procedure of Udenfriend et al. (1955), followed by twodimensional paper chromatography (Jepson, 1955).

\section{Results}

(1) Does Iproniazid Benefit Patients with Depression?-Twenty-six of the 50 patients improved during treatment with iproniazid. Twelve of these were defined as having responded to iproniazid and 14 as having a "coincidental" improvement. Twenty-
TABLE III

RESULTS

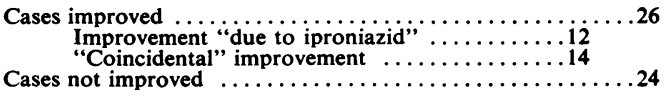

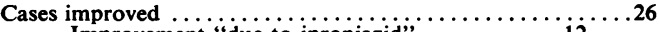
Improvement "due to iproniazid" . . . . . . . . . . . . "Coincidental" improvement ...............

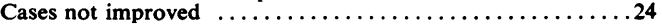

four patients did not improve (Table III). The improvement in patients defined as having responded to iproniazid usually began during the second and third weeks of treatment and this delay was not shortened by increasing the dose of the drug. There appeared to be no advantage in giving iproniazid in doses greater than $200 \mathrm{mg}$./day. On the other hand, some patients relapsed on dosage lower than $150 \mathrm{mg}$./day.

Side-effects of iproniazid at the dosage used in the present investigation were common. The most frequent were increase in weight, fluid retention, hypotension and postural hypotension, palpitations and throbbing headache, hesitancy of micturition, and impotence. The increase in weight was sometimes marked, up to 2 st. in two months. Studies with ${ }^{24} \mathrm{Na}$ have shown that this weight increase cannot be explained simply by water retention (Gibbons, J. L., and Pare, unpublished results). In this series there were no cases of peripheral neuro- $\frac{\Omega}{\mathbb{D}}$ pathy. One of the patients in our series died from acute hepatic necrosis (Pare and Sandler, 1959). When it became known that liver damage occasion- 8 ally follows administration of the drug, standard tests of liver function were carried out routinely inc 24 patients. Serum bilirubin, thymol turbidity, zinc sulphate turbidity, alkaline phosphatase, and serum proteins showed no significant abnormality. Estimation of serum glutamic-oxaloacetic transaminase activity which has recently come into extensive use as an index of hepatocellular damage was also carried out in 29 patients and showed significant changes in nine of them (Pare and Sandler, 1959).

By definition, patients who improved with iproniazid but did not relapse when placebo was substituted, were termed "coincidental" improvements. In the group defined as having responded to iproniazid, there was no evidence that iproniazid cut short their depressive illness, but rather that it provided symptomatic relief.

(2) Can Patients Responding to Iproniazid be Differentiated Clinically or Biochemically from Those Who Do Not?-Clinical assessment did not differentiate the patients who failed to improve with treatment either from patients who responded to iproniazid or from those who improved "coincidentally" (Table I). Estimations of urinary 5HIAA 


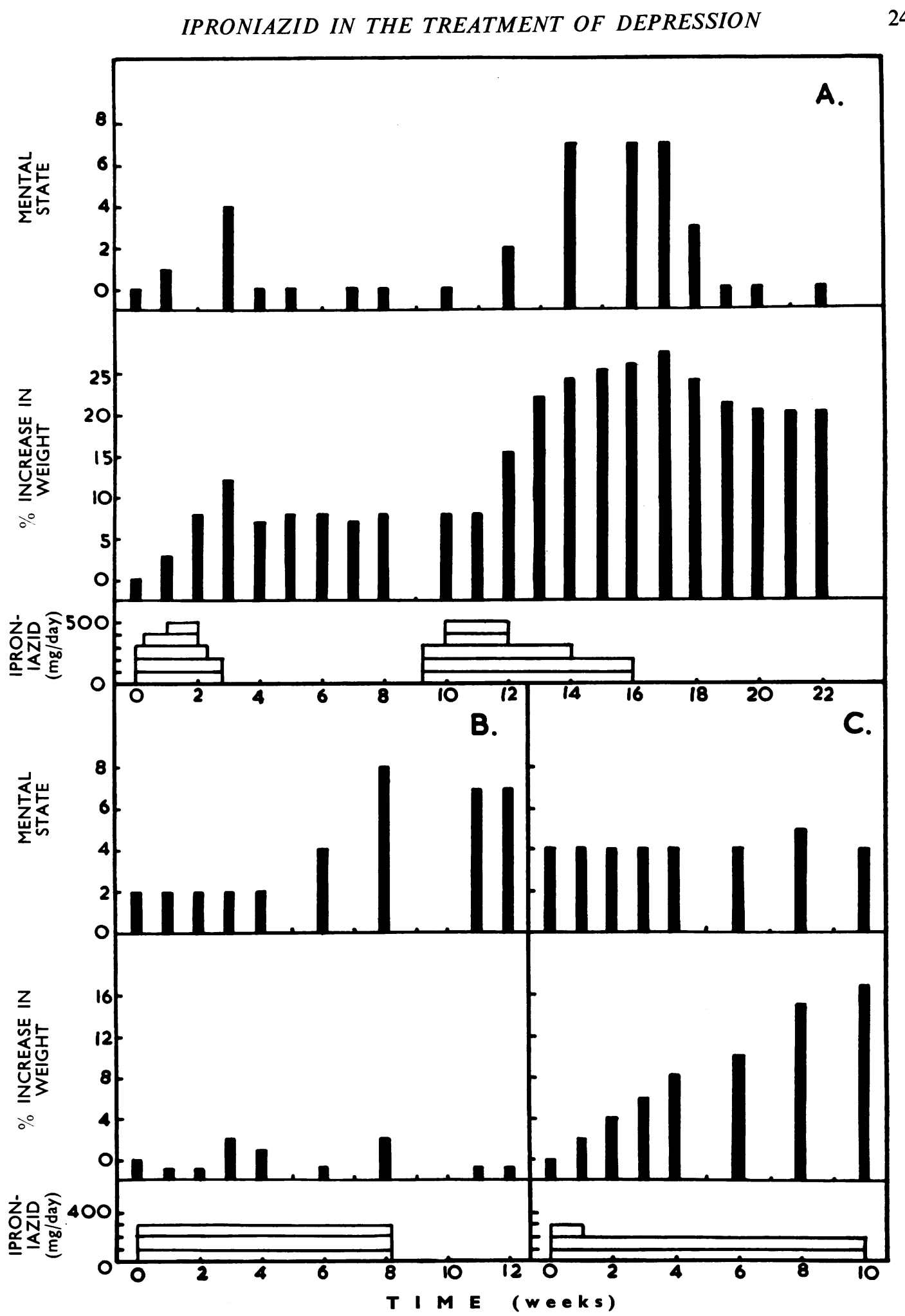

FIG. 1.-The effect of iproniazid on the weight and mental state ratings (Table II) in three typical patients.

A. Improvement due to iproniazid therapy.

C. Not improved by iproniazid. 
on 22 patients before iproniazid therapy appeared to differentiate between the groups (Table IV) and reached levels of significance when patients who responded to iproniazid were compared with those who did not.

TABLE IV

MEAN VALUES FOR URINARY 5-HYDROXYINDOLEACETIC ACID (SHIAA) IN EARLY MORNING SPECIMENS OF URINE COLLECTED BEFORE
IPRONIAZID THERAPY

\begin{tabular}{l|c}
\hline & $\begin{array}{c}\text { 5HIAA } \\
\text { (mg./g. creatinine) }\end{array}$ \\
\hline 9 patients improved "due to iproniazid" & $3.0 \pm 0.50$ \\
6 patients not improved with iproniazid & $\begin{array}{c}4.5 \pm 0.75 \\
7 \text { patients improved "coincidentally" to } \\
\text { iproniazid therapy }\end{array}$ \\
\hline
\end{tabular}

TABLE V

MEAN VALUES FOR URINARY 5-HYDROXYINDOLEACETIC ACID (5HIAA) IN NINE PATIENTS BEFORE AND DURING ADMINISTRATION OF IPRONIAZID

$\left.\begin{array}{c|r}\hline & \text { Mean 5HIAA (mg./g. creatinine) } \\ \hline \text { Before iproniazid } & 3.7 \pm 0.74 \\ \text { During iproniazid } & 2.6 \pm 0.46\end{array}\right\} 0.1>$ P $>0.05$

Concentrations in urine of 5HIAA from the nine patients examined before and during treatment were lower during iproniazid administration, although this fall did not reach statistical significance (Table V). No abnormal metabolites were seen on these chromatograms.

(3) In Patients Responding to Iproniazid, is Benefit Due to Changes in Brain Concentrations of 5HT, to Changes in Concentrations of Catechol Amines, or to Both? - In animals, both 5-hydroxytryptophan (5HTP) and 3, 4-dihydroxyphenylalanine (DOPA) are known to increase the brain concentrations of 5HT and catéchol amines respectively (Udenfriend, Weissbach, and Bogdanski, 1957; Carlsson et al., 1958). It is not quite clear which particular catechol amine concentration is increased during DOPA administration. Carlsson, Lindquist, Magnusson, and Waldeck (1958) claim to have detected an increase in dopamine which, they state, is present in considerable concentration in rabbit brain. They could find no increase in noradrenaline. Shore and Olin (1958), however, state that noradrenaline makes up the greater proportion of brain catechol amines.

Patients who were known to "respond" to iproniazid were given DL-5HTP and DL-DOPA by intravenous injection at intervals of at least a day, at the same time of the day, and in random order. Three patients were given the drugs in dosage of $12.5 \mathrm{mg}$. while receiving iproniazid but during the period of therapy before improvement was expected. Three patients were given the drug in the absence of iproniazid. In this group the dosage ranged from $25 \mathrm{mg}$. of each drug in a single injection to $150 \mathrm{mg}$. 5HTP and $275 \mathrm{mg}$. DOPA, each over a 48-hour period. Neither clinical nor psychological assessments (kindly done by Dr. J. C. Brengelmann) demonstrated any alleviation of the depression by either drug. In addition, one patient was given 5HTP and DOPA together, in doses of $12.5 \mathrm{mg}$. of each subcutaneously twice daily for 16 days. No improvement in the depression was noted clinically.

\section{Discussion}

A number of workers have used iproniazid in the treatment of depression (Smith, 1953; Ayd, 1957; Dally, 1958; Ferreira and Freeman, 1958; DeVerteuil and Lehmann, 1958; Symposium, 1958, on iproniazid), usually in a dosage of 100 to $200 \mathrm{mg}$./day. Of a total of 353 patients, $190(54 \%)$ were said to have improved. Comparison with the present investigation is difficult, as we studied only those cases of depression which were considered suitable for electroconvulsive therapy. However, taking the total number of patients in the present investigation $\doteq$ who improved, whether "coincidentally" or in 을 response to iproniazid, the $52 \%$ improvement compares closely with those reported by othe $\rightarrow$ workers.

This alleviation from depression was bought a the price of side-effects which were pronounced and frequent and one patient died from acute hepatie necrosis. Although it is difficult to interpret the finding of a raised serum glutamic-oxaloacetic transaminase in almost $30 \%$ of our patients, we would suggest that any rise detected in routine weekly estimations should, in the present state of our knowledge, be treated as presumptive evidence of liver damage, and the drug be discontinued (Pare and Sandler, 1959).

In this investigation, as with others reported, there is a characteristic delay before improvement occurs. This delay is not shortened by increasing the dosage of iproniazid. The fact that neither 5HTP, DOPA, nor a combination of these two drugs, alleviated the depression in patients who responded to iproniazid does not support the suggestion that the drug acts directly by increasing the brain concentrations of 5HT or catechol amines. However, the 5HTP and DOPA may have been given to our patients in too small a dosage or for too short a period of time, for the pre-treatment concentrations of urinary 5HIAA tended to be lower in patients who subsequently improved. However, we were unaware at the time of the high concentration of 5HT in bananas 
(Anderson, Ziegler, and Doeden, 1958) which were not excluded from the patients' diet. Our readings may not, therefore, be a true index of endogenous 5HT metabolism.

One of the many possible explanations of its action is that iproniazid allows the diversion of certain metabolic processes through alternative pathways. In animals given large doses of iproniazid, Weissbach, Redfield, and Udenfriend (1958) reported that an O-glucuronide conjugate of 5HT appears in the urine, but this detoxication product is likely to be inert. In the present investigation, and using much smaller doses of iproniazid than those used in animals by Weissbach et al. (1958), we were unable to find any abnormal metabolites.

Perhaps of most interest is the question whether iproniazid is a general euphoriant or whether it acts only on patients whose depression is due to a specific metabolic abnormality which has yet to be identified. The striking response to iproniazid noted in some patients compared with the apparent ineffectiveness of the drug in others suggests that the latter may be true.

\section{Summary}

A controlled trial of iproniazid on 50 patients with depression showed that 26 of them improved and that the improvement in at least 12 of these was due to the drug. The danger of liver damage was stressed.

An attempt was made to differentiate these groups and to determine the mode of action of iproniazid in those patients who responded. Methods used included parenteral administration of 5-hydroxytryptophan and 3, 4-dihydroxyphenylalanine and assessment of urinary 5-hydroxyindole excretion.

We are grateful to Professor A. J. Lewis and the physicians at the Bethlem Royal and the Maudsley hospitals for their cooperation in this trial; to Miss Lilith Emslie and Miss Doreen Crabtree, Royal Free Hospital, for skilled technical assistance, and to the Royal Free Hospital Endowment Fund and Roche Products Limited, for defraying their respective salaries; we are also grateful to Dr. J. Marks of Roche Products Limited for a generous supply of "marsilid" tablets and placebo, and for his advice.

\section{REFERENCES}

Anderson, J. A., Ziegler, M. R., and Doeden, D. (1958). Science, $127,236$.

Ayd, F. J.'(1957). Amer. J. Psychiat., 114, 459.

Bogdanski, D. F., Weissbach, H., and Udenfriend, S. (1958). J. Pharmacol., 122, 182.

Brodie, B. B., Pletscher, A., and Shore, P. A. (1955). Science, 122,

Carlsson, A., Shore, P. A., and Brodie, B. B. (1957). J. Pharmacol., $120,334$.

Lindquist, M., Magnusson, T., and Waldeck, B. (1958). Science, 127,471 .

Dally, P. J. (1958). Brit. med. J., 1, 1338.

Deshaies, G., Richardeau, N., and Dechosal, F. (1957). Ann. méd.psychol., 115, 417.

DeVerteuil. R. L., and Lehmann, H. E. (1958). Canad. med. Ass. J., 78, 131 .

Ferreira, A. J. deL., and Freeman, H. (1958). Amer. J. Psychiat., 114,933 .

Garattini. S., and Valzelli, L. (1957). In Psychotropic Drugs, p. 428. Ed. Garattini, S., and Ghetti, V. Elsevier Publishing Co., Amsterdam and London.

Hare, R. S. (1950). Proc. Soc. exp. Biol. (N.Y.), 74, 148

Jepson, J. B. (1955). Lancet, 2,1009 .

Lemieux, G., Davignon, A., and Genest, J. (1956). Canad. med. Ass. J., 74, 522 .

Pare, C. M. B., and Sandler, M. (1959). Lancet, 1, 282.

Pletscher. A., and Bernstein, A. (1958). Nature (Lond.), 181, 1133.

Shore, P. A., and Olin, J. S. (1958). J. Pharmacol., 122, 295.

Sjoerdsma. A., Smith, T. E., Stevenson. T. D., and Udenfriend, S. (1955). Proc. Soc. exp. Biol. (N.Y.), 89, 36.

Smith. J. A. (1953). Amer. Practit. Dig. Treatment, 4, 519.

Spector, S., Prockop, D., Shore, P. A., and Brodie, B. B. (1958). Science, 127, 704.

Symposium on the Biochemical and Clinical Aspects of Marsilid and other Monoamine Oxidase Inhibitors (1958). J. clin. exp. Psychopath., 19, Suppl. 1.

Udenfriend, S., Titus, E., and Weissbach, H. (1955). J. biol. Chem. 216, 499 .

216, 499. $H$.

Von Euler, U. S., (1956). Noradrenalin. C. C. Thomas, Springfield, Illinois.

Weissbach, H., Redfield, B. G., and Udenfriend, S. (1958). Fed. Proc., 17, 418.

Zeller, E. A., and Barsky, J. (1952). Proc. Soc. exp. Biol. (N.Y.), 81, 459. 